\title{
DOS GALHOS ȦS GRADES: COTIDIANO E RELACÕES INTERESPÉCIES NO "BOSQUE". REFLEXÕES SOBRE AS INTERACÕES FACE A FACE ENTRE HUMANOS E MACACOS-DE-CHEIRO (SAIMIRI SCIUREUS SCIUREUS) NA CIDADE (BELÉM-PA)
}

\author{
Flávio Leonel Abreu da Silveira* \\ Matheus Henrique Pereira da Silva** \\ Universidade Federal do Pará - Brasil
}

Resumo: A partir da experiência etnográfica junto às paisagens do zoo do Bosque Rodrigues Alves, na cidade de Belém (PA), nos voltamos às relações entre humanos e não humanos, mais diretamente às interações cotidianas entre tratadores, biólogos, médicos veterinários e a espécie de primata conhecida por mico-de-cheiro (Saimiri sciureus sciureus), bem como as interações com os visitantes e transeuntes que deambulam no interior e no entorno da área verde, envolvendo cuidados sob a ótica do bem-estar animal, no caso da equipe da fauna, até as relações de comensalismo, possibilitando experiências multissensoriais entre humanos e micos, apontando para deslocamentos quanto à perspectiva e às atitudes em relação aos não humanos na urbe amazônica.

Palavras-chave: Amazônia, área verde, cidade, zoo.

Abstract: Based on the etnographic experience in the zoo of Bosque Rodrigues Alves, in the city of Belém (PA), we focus on the relationships between humans and nonhumans, specifically the daily interactions between carers, biologists, veterinarians and the primate specie known as squirrel monkey (mico-de-cheiro) (Saimiri sciureus sciureus), as well as the interactions with the visitors and passersby that walk in and around the green area, involving the care for the animals' well-being, in this case the fauna team, and even the relationships of commensalism, allowing multisensorial

\footnotetext{
*Contato: flabreu@ufpa.br

** Graduando em Ciências Sociais (bolsista Pibic/CNPq). Contato: matheusk11@hotmail.com
} 
experiences between humans and monkeys, pointing to the displacement of perspectives and attitudes towards the non-humans in the urban Amazônia.

Keywords: Amazon, city, green areas, zoo.

\section{Paisagens coexistenciais: interacõos entre humanos e primatas urbanos}

Neste artigo, a partir de etnografia ${ }^{1}$ realizada no Jardim Botânico Bosque Rodrigues Alves (JBBRA), em Belém, propomos uma reflexão acerca das relações interespecíficas humanos-não humanos, ou ainda, entre símios humanos e primatas não humanos, que nos coloca questões senão apenas de classe ou de ordem - se consideramos a proximidade filogenética entre ambos os grupos, certamente algumas ponderações acerca do olhar e de suas interações como um fenômeno de relação entre diferenças, quiçá de ontologias. É preciso ampliar a potência do olhar e do seu (des)encontro (Silveira; Silva, 2015) entre seres sencientes, desde aquilo que os aproxima até aquilo que os tensiona ou comunica. Não se trata de perscrutar as verdades do olhar não humano, o que seria se não difícil, até certo ponto, impossível, mas sim, de mediante um cruzamento de olhares refletir sobre a possibilidade interpretativa de uma comunicação interespecífica na cidade.

Portanto, se, como aponta laconicamente John Berger (2009), o zoo é o local onde se daria o desencontro entre o animal e o humano, isso seria uma verdade diante dos horrores da prisão e de sua devassidão panóptica, com uma impossibilidade ética de vislumbrar o Outro não humano pela sua diferença - ou, simplesmente de objetificá-lo até a negação de sua alteridade e o seu aprisionamento numa jaula. Enfim, o desencontro, aqui, se daria em um distanciar-se de alteridades como oposições binárias excludentes: ou se é humano ou não, ou se é gente ou bicho, ou se é racional ou irracional, ou se é civilizado ou selvagem, ou... ou. Persiste uma camada espessa de arrogâncias, expressões de senso comum e de ignorâncias em relação ao Outro não humano.

Todavia, se partirmos do pressuposto que os prendemos para melhor vislumbrá-los e, a partir da distância nos enxergarmos como humanos, pensamos

1 Trabalho concebido a partir do Projeto de Bolsa de Produtividade do CNPq, intitulado "Estudo antropológico das interações de humanos com os não-humanos no Bosque Rodrigues Alves, na cidade de Belém (PA). Paisagens de evasão, conservação da biodiversidade e imaginário urbano".

Horizontes Antropológicos, Porto Alegre, ano 23, n. 48, p. 99-127, maio/ago. 2017 
que, por mais patética que seja tal constatação, neste artigo, quando se trata de considerar as relações entre os animais de vida semilivre e os profissionais nomeados de "tratadores" - incluindo-se, ainda, outros agentes -, cuja relação com os primeiros animais mostra-se intensa sob a ótica do bem-estar animal, é preciso refletir sobre as negociações de sentidos, as permutas e os cruzamentos de olhares para a obtenção de uma coexistência temporária no zoo que envolve diversos engajamentos multiespecíficos, objetivando o estabelecimento de condições propícias à continuidade da vida.

Sendo assim, temos outra forma de experimentação/compartilhamento do olhar que seria própria aos jogos entre naturalização da cultura e culturalização da natureza (Escobar, 2005), quando se torna exequível (e "natural") manter não humanos em cativeiro para o nosso deleite, criando, quando possível, cenários miméticos de uma natureza-artifício na qual o cativo figura, e fulgura, decalcado do meio, como a expressão de sua existência [a natureza] distante. Se há uma coexistência assimétrica nessa forma de experienciar a zoopolis (Wolch, 1996), nota-se que ela precisa ser mediada pela possibilidade de convívio e de permanência nos espaços praticados (De Certeau, 1994), envolvendo uma multiplicidade de affectés (Favret-Saada, 1990) e afecções (Deleuze; Guattari, 1980). As pessoas possuem um grande interesse e carinho pelos micos-de-cheiro que deambulam pelo "Bosque" - como é comumente chamada a área verde estudada -, mas certamente existem algumas tensões que reverberam nos mundos possíveis dos viventes em relação, as quais são constituídas nas interações ecológicas e simbólicas que ocorrem cotidianamente no zoo.

As relações entre humanos e micos nos espaços do JBBRA implicam a existência de um jogo simmeliano (Simmel, 1983) de proximidade e distância, de enquadramento proxêmico (Hall, 1986), que define não apenas marcas e sinais de suas presenças nas paisagens construídas do Bosque, mas a possibilidade de trocas e de interagências complexificadoras das dinâmicas ecoantropológicas nas paisagens coexistenciais interespecíficas, como expressões híbridas/mestiças de humanos e não humanos em relação.

Portanto, se a presença humana no interior do Bosque manifesta-se, por vezes, pelo grande descarte e acúmulo de $\operatorname{lixos}^{2}$ - especialmente nos finais

2 Sobre a presença do lixo urbano como um indicativo "arqueológico" de sítios com a presença humana ver o trabalho de Magni (2006). 
de semana -, percebe-se que, quanto aos micos, os seus rastros (restos de comidas dispersos pelo chão e no gradeado), pela via do descarte, também são uma realidade. Sendo assim, tais evidências indicam que ambos, de maneiras diversas, obviamente, inscrevem seus trajetos no local também por meio da dispersão de resíduos. A questão envolvendo os resíduos humanos tem impacto direto no forrageamento realizado pelos pequenos primatas, que se banqueteiam com os restos ou mesmo pela oferta de alimentos, provocando movimentações entre os bandos. Os micos tendem a acompanhar as movimentações dos humanos, que por sua vez deslocam o seu olhar em direção aos primatas buscando contato. O que fica evidente é a vontade recíproca de interagir, movida por motivos distintos que mesclam interesse alimentar de uma parte e representações acerca da natureza de outra. De qualquer maneira, ambos os agentes estão implicados numa interação ecológica interespecífica denominada de comensalismo (Radhakrishna; Sinha, 2011).

Tais agenciamentos não somente compõem imagens e misturas de natureza e de cultura, como possibilitam refletir sobre problemáticas acerca de como se efetua tal convívio diário, além, é claro, dos engajamentos possíveis de humanos junto aos outros-animais na cidade. Permite-nos refletir sobre as implicações das práticas e das atitudes humanas que remontam aos problemas de conservação da espécie (quanto à ética e quanto ao bem-estar animal), seja pelo manejo no zoo, nesse caso, realizado pelos tratadores - em aliança com biólogos e médicos veterinários -, e/ou nas atividades de compartilhamento de espaço e de comida junto a humanos no interior e no entorno do Bosque.

Ao acompanharmos a equipe da fauna que atua no local, os visitantes nas diversas intermediações do Bosque e os passantes em seu entorno, foi possível o estabelecimento tanto de conversas "informais" como de entrevistas, objetivando uma experimentação etnográfica que tornasse viável a descrição de zonas de contatos e de engajamentos N-dimensionais (Fuentes, 2010), presentes na construção de dinâmicas ecológicas próprias ao devir das relações interespecíficas, de como se desdobram enquanto fenômenos nas paisagens. Elas envolvem ritmos e atividades diárias incidindo em dinâmicas da/na cidade - também referentes à construção de nichos negociados entre humanos e não humanos - imanentes à impressão de marcas na paisagem (Berque, 1998) e às territorialidades constituídas na interação, e também referentes à construção de nichos negociados entre humanos e não humanos. Como apontou Donna Haraway (2003) acerca das espécies, problematiza-se o viver com 
entre animais humanos e não humanos implicando uma miríade de organismos vivos, suas disposições e motivações na tessitura de suas interações.

Intentamos neste artigo realizar uma descrição das maneiras diversas pelas quais os agentes (tratadores, biólogos, médicos veterinários, comerciantes e passantes) se distribuem ao longo das paisagens, configurando, segundo os seus movimentos - sempre relacionais -, zonas de contatos potenciais de (des)encontros, envolvendo humanos e não humanos, especialmente os micos-de-cheiro. Como já esboçado nos parágrafos anteriores, entre outros engajamentos, nos voltamos mais diretamente para a questão do forrageio e suas relações com a presença humana naquele contexto, pois os macacos circulam em bandos e, após compartilharem ou receberem o alimento das pessoas, dispersam-se e desaparecem; em outros momentos circulam pelo gradeado interagindo de variadas maneiras, ultrapassando os limites esquadrinhados para as práticas do espaço (De Certeau, 1994) - diante de suas singularidades em termos de escolhas quanto à interação com humanos ${ }^{3}$ - e que são "destinadas" aos entes de vida semilivre que ocorrem no Bosque.

\section{Sobre bandos, tratadores e engajamentos multiespecificos no zoo}

A espécie de primata Saimiri sciureus sciureus é relativamente pequena, estima-se o tamanho de seu corpo, em média, em $30 \mathrm{~cm}$ e a cauda, entre 30 e $40 \mathrm{~cm}$. O peso de uma fêmea adulta gira em torno de 500 a $750 \mathrm{~g}$, já um macho teria a correspondência de 700 a 1100 g (Bicca Marques; Silva; Gomes, 2006); os indivíduos apresentam pelagem com tonalidades amarelo-esverdeadas e pretas. Trata-se de uma espécie de hábitos diurnos. Pela manhã, forrageiam, tornando-se visíveis em suas movimentações pelo Bosque, quando entram em contato com os humanos no interior e em seu entorno; também deambulam à tarde em busca de comida. Ao longo do dia, intercalam atividades de coleta de alimentos, socialidades intragrupo e descanso; à noite, dormem em grupo.

\footnotetext{
A bibliografia sobre interações entre humanos e primatas é significativa. Aqui, citamos aquelas que consideramos as mais representativas para o artigo em questão, tais como Fuentes (2007, 2010); Fuentes, Shaw e Cortes (2007); Leite, Duarte e Young (2011); o trabalho de Magalhães (2008) é interessante para a reflexão que realizamos. A discussão realizada por Gordo et al. (2013) sobre o sauim-de-Manaus (Saguinus bicolor), espécie de primata que habita fragmentos florestais na área urbana manauara, é inspiradora.
}

Horizontes Antropológicos, Porto Alegre, ano 23, n. 48, p. 99-127, maio/ago. 2017 
A alimentação consiste basicamente em frutas da época, resinas de vegetais, insetos, pequenos pássaros, rãs, aranhas, ovos de aves, flores e caracóis espalhados por todo o Bosque, tornando-se fonte de disputas dentro do próprio bando no qual costumam locomover-se, mas também entre outros grupos da espécie que se distribuem territorialmente na área verde urbana. Estima-se a quantidade de micos no Bosque entre 40 a 50 indivíduos, distribuídos em bandos distintos. Durante uma conversa com o primatólogo José Silva Júnior (em 07/08/2014), do Museu Emílio Goeldi, ele informou que nos anos 80 teria libertado 6 ou 8 micos-de-cheiro no Bosque, e a partir daí a população de desenvolveu, certamente com o acréscimo de outros indivíduos.

Sendo o local uma área voltada à conservação da biodiversidade e à preservação da cobertura vegetal, há uma série de elementos que contribuem para a proliferação da espécie (Baldwin, 1985; Baldwin; Baldwin, 1981). Um dia pela quarentena (em 16/06/2015), enquanto acompanhávamos Távison, biólogo que atua no Bosque, ele afirmou, referindo-se aos micos, que a área é "um ambiente ideal para eles se reproduzirem", em função da disponibilidade de alimentos e de recursos presentes naquele fragmento urbano de "floresta neotropical". Os primatas que vivem no fragmento de floresta urbana possuem seu ciclo de reprodução ligado à sazonalidade climática, e desse modo estaria relacionado ao período de maior precipitação pluviométrica, pois "eles se reproduzem mais nesse período", acrescentou Gelson (em 18/06/2015).

Os micos compõem o acervo da fauna de vida semilivre do JBBRA. "Esses macacos são chamados de macaco-de-cheiro, vulgarmente chamados, porque são verdinhos, parece um cheiro-verde. São pequenos!”, comentou o tratador Moisés em conversa realizada no setor da fauna (em 20/09/2014). No entanto, sabe-se que tais animais recebem essa denominação devido a suas práticas de se limparem cuidadosamente com as patas. Depois, costumam urinar sobre a cauda e a encharcam com as mãos, gerando um "mau” cheiro, daí a alusão ao cheiro.

Ao caminharmos ao longo do Bosque, mas também nas calçadas do seu entorno, é possível perceber que há uma zona de contato envolvendo o compartilhamento de nichos, que se traduzem em formas de convívio e de vizinhança, com possibilidades de interações face a face, pois os primatas, preferencialmente, circulam pelos estratos vegetais baixos de até 15 metros e, não raro, junto às avenidas movimentadas (Magalhães, 2008), na medida em 
que coexistem nas paisagens do Bosque através de linhas de engajamentos com outras espécies de vida livre ou em cativeiro, com tratadores, biólogos, médicos veterinários, ou mesmo com visitantes e/ou transeuntes que circulam naquele contexto.

Os tratadores realizam suas atividades diárias junto às jaulas e gaiolas, sendo responsáveis pela composição do plano alimentar dos animais confinados do zoo, e, acompanhados por biólogos e médicos veterinários, se encarregam do bem-estar das espécies representativas da biodiversidade local. No entanto, a sua atuação não diz respeito apenas aos animais em cativeiro, pois cotidianamente disponibilizam aos micos-de-cheiro cerca de duas basquetas ${ }^{4}$ matinais contendo frutas, como: bananas, mamões, mangas, entre outras, de acordo com a época de frutificação das espécies vegetais. Há, portanto, uma preocupação com a presença dos primatas não apenas pelo fato de serem muito numerosos e, por isso, necessitarem de suplemento alimentar em relação ao que encontram nas matas do JBBRA, mas também devido aos seus constantes agenciamentos de táticas de pilhagem em relação aos alimentos fornecidos aos animais em cativeiro, como deixaremos mais claro adiante.

A distribuição das basquetas foi modificada ao longo do período em que realizamos a etnografia: primeiramente, localizavam-se em frente à antiga cozinha, sobre o tronco de uma árvore cortada e a outra na grade lateral do recinto dos jabutis e guarás. Desde agosto de 2015 , devido à construção e à inauguração ${ }^{5}$ da nova cozinha, da reforma do setor extra da fauna, entre outros, um dos comedouros foi realocado para frente da nova cozinha e o outro continuou no mesmo lugar. Os micos demoraram algumas semanas até encaminharem-se rumo ao novo lugar do comedouro, enquanto isso, aos poucos, os tratadores foram diminuindo a porção dos alimentos na antiga localidade, observando a movimentação dos animais.

A partir de nossas observações, é possível perceber que por volta das sete e meia da manhã, os grupos de micos começam a sua agitação nas proximidades da cozinha, pois os tratadores ficam incumbidos de distribuir os alimentos até as oito e meia da manhã. Trata-se da "primeira alimentação do dia, antes

\footnotetext{
4 Categoria nativa utilizada por tratadores e biólogos referente ao recipiente de alumínio onde os alimentos são servidos.

5 Para mais informações, ver Bosque... (2015).
} 
deles começarem a circular atrás de insetos", afirmou Gelson. Além disso, há distribuição de um complemento alimentar, pois "tem a ração que a gente coloca junto com as frutas, uma ração para primatas", acrescentou o biólogo Távison (em 16/06/2015).

Os pequenos primatas estão habituados ao ritual cotidiano de comensalidade. Portanto, diariamente aguardam a dádiva nutricional que lhes é ofertada. Todavia os micos exigem certa pontualidade na distribuição do repasto, pois caso ocorra atraso em relação ao horário da entrega do alimento, segundo Neto (em 07/05/2015), outro biólogo que atua no Bosque, mostram-se impacientes, uma vez que:

Acaba variando [o horário de distribuição]. Ontem, por exemplo, o nosso fornecedor de frutas acabou se atrasando, então deu nove e meia e a gente não tinha colocado essa bandeja que eu te falei, com bananas e mamão, então eles foram à porta da cozinha reclamar: "Ei! Cadê a nossa comida?" Então eles apareceram, entendeu?

Vários primatas descem das árvores e avançam pela estrutura física da cozinha, não raro, adentrando-a. "Os macacos que aparecem geralmente no setor de fauna [...] cozinha da fauna, são os macacos... que priorizam o bando" (ênfase nossa), disse Moisés. Sobretudo em relação àqueles que se alimentam nos vasilhames dispostos, pois em certas ocasiões alguns micos circulam "sozinhos" pelas espacialidades do Bosque. Algumas vezes, "roubam" os mantimentos que estão em vias de preparo, ou que permanecem depositados em guarda de mantimentos e, mesmo, nos carros de mão, destinados aos animais que se encontram nos recintos à espera da visita dos tratadores, que distribuirão seus alimentos.

Certo dia (em 24/10/2015), numa de nossas visitas ao local, o tratador Gelson colocou bananas na bandeja em frente à antiga cozinha e afirmou: "Não demora eles chegam aqui! Sentem o cheiro da fruta!" Assoviou, bateu na bandeja com uma faca e produziu outras vocalizações, chamando-os. Então, indagamos a Gelson: "E o senhor chamando assim, eles vêm?" "Vêm!", respondeu. Logo pudemos observar que desciam vários macacos, movimentando-se rapidamente pelos galhos e apanhando as frutas. Velozes, buscavam os alimentos, em meio a alguns conflitos, e sumiam na mesma velocidade que apareciam. Em outra ocasião caminhamos e conversamos com o biólogo Neto (em 07/05/2015): 
- Como eu te falei o cheiro do que os tratadores cozinham aí, a alimentação para o peixe-boi e outros animais acaba atraindo eles, também, ou então, pelo Bosque. O cheiro os atrai. Eles acabaram de comer, se for dar comida eles vão comer.

- Eles têm o olfato mais desenvolvido?

- Os primatas têm o olfato, a audição, os sentidos mais desenvolvidos que os nossos. Então, qualquer barulho de galhos eles ficam alertas!

Aqui é preciso deixar claro que essa possibilidade evoca a potência mesma da explosão de um acontecimento: encontro interespécies, carregado de intencionalidades e de sentidos, onde os (des)encontros e as partilhas de afinidades entre seres vivos (consubstanciados nas imagens da natureza e da cultura amazônica) indicam formas de socializações a partir de experimentações multissensoriais, engendradas no caminhar com o outro no mundo urbano (Pink, 2007, 2008, 2009) - a exemplo do cheiro dos alimentos e/ou o "chamado" dos tratadores - bem como nos contatos e alianças com os não humanos e viventes outros em meio a uma floresta (botânica e simbólica), e por isso em seus desenvolvimentos e crescimentos along lines (Ingold, 2011), nas quais as relações configuram formas interacionais de organismos entre si. Trata-se de emaranhamentos de linhas e devires no espaço-tempo que conformam sociações interespecíficas que se associam desde as suas diferenças coligadas nas paisagens.

Ao depositarem os alimentos na segunda basqueta, percebe-se que os micos descem para buscá-los. Eles exercem tal agência junto aos comedouros dos recintos de diferentes espécies em cativeiro, quando ocorre o convívio entre os primatas e outros animais. No chamado recinto dos jabutis, os pequenos primatas interagem com duas espécies de jabutis e aves como araras, garças e guarás, por exemplo. Outra interação entre não humanos se dá pelo "roubo" de comida pelos grupos de micos nesse mesmo recinto ou noutros, exigindo que os tratadores disponham de mais alimentos para a promoção do comensalismo, uma vez que é sempre necessário contar com a margem de saque realizado pelos primatas durante a distribuição dos alimentos. Atualmente, durante as novas adaptações exigidas pelo Ibama, as araras foram deslocadas para o lado esquerdo ao recinto com a construção de novas arquiteturas feitas para o seu deslocamento sobre um córrego do pequeno lago. Entretanto os micos continuam, cotidianamente, buscando os alimentos, sendo necessário que o Neto (biólogo) os vigie, afastando-os com um pequeno jato de água, lançado durante a sua vigília ante a aproximação dos micos.

Horizontes Antropológicos, Porto Alegre, ano 23, n. 48, p. 99-127, maio/ago. 2017 
Certamente, o comensalismo implica formas de socialidades com os tratadores, seja no que se refere aos animais confinados nos recintos ou aos pequenos primatas, portanto os animais se aproximam dos humanos. Há uma experiência proxêmica que varia de acordo com a espécie em relação, joga-se o social na tensão entre proximidade e distância, negociada a partir do reconhecimento recíproco e convivial das alteridades. Não se trata de mera convivência, mas de uma experiência de convivialidade sutil e cotidianamente delineada pelo estabelecimento de laços interespecíficos complexos, onde os agentes se afetam reciprocamente, a exemplo da alteração no regime de tempo onde há um maior investimento nas interações como o forrageamento dos micos.

Sendo assim, ao receberem alimentos fáceis dos tratadores, passantes e/ ou dos visitantes, os primatas não enfrentariam certas situações que envolvem outros agentes na dinâmica ecológica e, nesses termos, não se exporiam às interações com predadores, pois nossas observações nos mostram que ao descerem em busca de bananas dispostas nas basquetas os micos evitam caminhar no solo, onde poderiam entrar em relações de predação, especialmente com jiboias (que predam tanto no sistema arbóreo quanto no solo), espécie de serpente não venenosa encontrada no Bosque.

As negociações aí são múltiplas e emergem de vetores distintos, diariamente. Tratadores e animais cativos; tratadores e micos; espécies diversas entre si que compartilham o mesmo cativeiro; espécies confinadas em recintos e micos - mas, também, com cotias, pacas, sabiás brancos, entre outros; e todo um sistema ecológico existente no Bosque. Os animais, dessa forma, compartilham entre si os alimentos preparados e servidos em basquetas de alumínio e bandejas de plástico espalhadas pelo recinto: no chão para os animais terrestres e sobre suportes de madeira para as aves. A observação de temporalidades relativas ao cronograma de alimentação compartilhado pelos animais cativos, mas também pelos primatas, aponta para a existência de táticas ligadas ao comportamento dos animais, que agenciam seus movimentos com a flora, as estruturas do zoo e outros materiais ao longo do Bosque, imputando ao tratador uma "negociação" de sentidos na dinâmica de (des)encontros cotidianos.

Os macacos, no decorrer do dia, também buscam forragear junto a outros recintos em busca de frutas. Assim, como agentes, engajam-se através de uma malha (Ingold, 2010, 2011) de materiais (galhos, gradis, bandejas, carros de mão, entre outros elementos) que envolvem agenciamentos com humanos

Horizontes Antropológicos, Porto Alegre, ano 23, n. 48, p. 99-127, maio/ago. 2017 
e outros viventes. No caso dos tratadores, os seus engajamentos dizem respeito aos processos vitais que são continuamente desenvolvidos no contexto do zoo, implicando práticas de conservação imanentes às deambulações que realizam e que constituem formas de socialidades com animais cativos, ou de vida semilivre como são os micos, justo ao longo dos seus trajetos pela área, uma vez que no caso dos pequenos primatas, tais relações são efetuadas no cruzamento cotidiano de tratadores e de micos-de-cheiro pelos espaços e instalações do Bosque. Ora, trata-se de interações interespecíficas que se dão a partir de seus caminhos traçados nas paisagens de coexistência, onde marcam (Berque, 1998) suas presenças mediante um emaranhado de movimentos, gestos, relações visuais recíprocas, odores e contatos possíveis nas interações humanas/não humanas, correlatas, ademais, às territorialidades humanimais construídas e negociadas desde as relações simbólico-práticas presentes no contexto do Bosque.

Durante as descidas dos micos em busca de alimentos é possível notar que, em certas ocasiões, quando há tentativa de tocá-los por parte das pessoas, ou quando são tocados, rapidamente movimentam-se tentando desviar ou se desvencilhar do contato, por vezes ensaiando "ataques", a exemplo de mordidas. Por certo, oferecem "resistências" e estabelecem "negociações" quanto à proximidade e ao contato; devido a isso, não se trata de meras reações comportamentais "influenciadas" por um ambiente externo, pois humanos e não humanos tornam-se companion-agents (Despret, 2013), efetuando engajamentos multiespecíficos entrelaçados em processos vitais de contatos e de trocas, nos quais se vinculam pela coexistência, desdobrando-se em jogos interespecíficos de negociações de gestos e símbolos em ato, como expressões interculturais mutuamente agenciadas. Cultura, aqui, não diz respeito ao humano per se, mas à própria invenção primata ao agenciar o agenciamento humano mediante táticas de jogar o jogo social com ele e, por isso, mesmo, de (re)inventar a cultura na ação como possibilidade interespecífica, como gesto e como forma social em devir com o humano.

Por outro lado, diante das recomendações estabelecidas de não tocar nos animais e de não alimentá-los, especialmente por ordem da administração e da equipe da fauna do Bosque, os tratadores Paulo Vitor e Gelson discorrem:

Exatamente, o animal fica até agressivo! Muitas vezes a pessoa pega no animal e não sabe pegar. Não tem aquela cautela pra pegar no animal. Essas coisas que 
podem acontecer. O bicho lhe bicar, lhe morder. Por que um animal desses, se você vê bem um animal desses aqui, um, por exemplo, esses saguis, esse macaco-de-cheiro que fica solto aí de bando, aí. Ele é um animal dócil, animal manso, mas se você pegar nele, ele vai lhe morder, que ele é acostumado solto e não vai querer que você incomode ele. Entendeu? Se uma criança pegar ele vai morder porque uma criança não sabe o que tá fazendo. $\mathrm{E}$ a pessoa não tem aquele conhecimento sobre a reação do bicho na hora, né. (Paulo Vitor, em 09/10/2014).

- Não, se tirar um pedaço de alguma coisa, dá na mão deles. Porque o macaquinho, ele desce. A gente sempre alerta pra não pegar neles, pra não tocar.

- Por quê?

- Porque eles atacam! Porque tu vai pegar um, aí um grita. Aí os outros tudo vão começar, aí vão querer te morder. (Gelson, em 09/10/2014)

O gesto humano de tocar noutro primata implica uma potência de afecções nas quais humanos e não humanos tornam-se "perigosos" entre si pelo contato: a possibilidade da veiculação de zoonoses de um ao outro e o ato violento de bater ou de ser mordido colocam ambos em tensão. É certo que no contexto do Bosque a busca humana pelo toque do animal é muito mais uma forma de congraçamento interespecífico que qualquer outra coisa; no entanto, a forma como os micos interpretam a agência humana, e a partir daí articulam gritos altos na presença de um suposto ato violento, prenunciando os perigos de tal encontro, tende a dinamizar todo o bando de macacos via comunicação do medo - o medo aqui é um vetor de relação interespecífica.

Em tais situações, a partir do toque conferido ou da tentativa dele associado à oferta de alimento, em pouco tempo junta-se um bando próximo aos humanos, configurando negociações de sentidos e de territorialidades no encontro a partir de suas movimentações cotidianas, seja pela relação visual recíproca ou pelo ato comensal. Portanto, espaços como as bancas de vendas de produtos comestíveis e as calçadas são praticados pelos primatas na interface com os humanos, emergindo um nicho espacial cujos "efeitos de borda" se tensionam com outros grupos da mesma espécie, uma vez que "são extremamente territoriais", como reforçou Moisés certa vez, disputando, assim, espaços de interação com os humanos. O estabelecimento de uma relação de distanciamento pelos micos-de-cheiro, que ficam à espreita, contribui para 0 desenvolvimento de suas habilidades de fuga, ou de desvio ante o contato humano. 
No caso dos tratadores, o "tocar" pode estar ligado a um estreitamento de vínculos com os animais no zoo, ou alguma relação especial com eles (Estebanez, 2008), pois os distanciamentos, entendidos como expressões proxêmicas, são erigidos no acesso privilegiado aos recintos e demais espacialidades do Bosque. A proximidade experimentada é constituída na frequente interação com o animal, sendo permeada por ambiguidades, podendo afetar a gestão de tratos e cuidados. Abaixo são evocadas outras imagens dos micos pelos tratadores Gelson e Moisés:

- Pode dar comida na mão pra eles, só não pode tocar de volta neles...

- Não pode tocar neles, dando a comida assim ele vem pega na tua mão com a mãozinha, deixar a banana e pegar neles, eles mordem mesmo! As pessoas pensam que são domesticados, domesticados assim que são mansos e tal... Mas não pode tocar... (Gelson, em 16/11/2014)

Mas eles são superdóceis, são agressivos quando estão em bandos, mas sozinhos são dóceis! Dificilmente a gente tem um acidente a nível de visitantes, a não ser que se queira pegar no animal ou o animal sentir acuado e pode atacar, mas fora isso são supertranquilos, sem problema nenhum. (Moisés, em 20/11/2014).

As condições climáticas e o regime pluviométrico variáveis, como observados no período da etnografia realizada (entre fevereiro de 2014 e agosto de 2016), produzem grandes impactos na economia dos tratos e dos cuidados a serem realizados naquele contexto, pois desde a estiagem e as altas temperaturas registradas com o fenômeno El Niño, há impacto no forrageamento dos micos ao longo do gradeado que delimita o Bosque, ou mesmo seus saltos pelos galhos e copas da flora tornam-se menos intensos, pois o forte calor tende a contribuir para um clima mais seco, diminuindo a incidência de chuvas, em detrimento dos elevados níveis de umidade e da emblemática chuva da tarde na capital paraense.

A circulação dos micos se dá principalmente nos horários de menor temperatura e com um maior sombreamento propiciado pelas árvores, como disse Moisés em uma conversa informal. Os animais sofrem sensivelmente com tais alterações ambientais que, por vezes, se desdobram em diversos relatos sobre problemáticas e acidentes com os não humanos, que nesse caso podem ocorrer com maior frequência.

Em decorrência de outras mudanças climáticas, como a chegada do intenso período de chuvas, há uma notável proliferação de viventes não humanos, 
tais como fungos, bactérias entre outros, que são potenciais agentes ecológicos de doenças e desequilíbrios no regime alimentar, distribuídos principalmente pelo vento, flora (a exemplo de árvores com galhos de curta poda) e pelos animais ao longo do Bosque. Outro acontecimento são algumas notáveis "ausências" no campo visual dos visitantes, especialmente os micos, que figuram normalmente em sucessivos encontros com os passantes no interior e no entorno do zoológico nos horários em que há maior demanda de alimentos. Durante sua circulação, os macacos obtêm comida via coleta/captura, ou pela distribuição por parte dos tratadores, por volta das dez da manhã e às quatro da tarde.

Algumas dessas imagens são evocadas no dialogo com o tratador Moisés (em 25/11/2014):

- E nesse período de chuva, você falou que muda a dieta deles...

- É, esse período de chuva agora já tá, muda um pouco em relação aos viveiros externos: nos casos dos patos verifica-se a comida, ela é posta bem mais cedo para eles tentarem aproveitar. Da feita que chove à tarde, inunda tudo e ninguém come mais nada. Então a gente também precisa de comedouros fechados, locais estratégicos pra isso, é o que a gente já observa também, oh! Percebeu?! A gente já não tem visto mais macaco-de-cheiro aqui! Antigamente descia aos "milhares" e ficavam aqui, ficavam gritando, esse horário agora. Por que não tem mais? Porque a gente tá em época de frutificação de árvores: açaí, manga, pupunha, taperebá, tucumã, tão tudo florescendo, tão tudo dando, tudo dando alimento. Então eles já, se não, eles estão todos aqui no Bosque, mas estão tudo atrás, de vez enquanto eu vejo uma manga caindo. Uma manga despencando, são eles que estão comendo. Aí, como têm em abundância aí, eles já sabem que tem aqui. Mais ou menos no período de maio, julho eles vão começar a descer de novo. Eles vão procurar, não tem mais onde achar. [...] Uma outra preocupação, também, porque é uma nova demanda de alimentação, é mais comida, mais banana, mais mamão [...] Hoje as araras já comem mais tranquilamente porque eles não estão atacando, mas nesse período aí, a gente tem que colocar tanto alimentação para eles quanto para as araras, senão eles roubam toda comida! Aí não tem como comer. A arara tem que descer para comer com o jabuti, batata doce... Então tudo isso, né! É uma época que contém açaí, eles comem açaí com as araras, açaí para os papagaios. Conforme a fruta da época, também animais comem, silvestres.

Os bandos de micos-de-cheiro operam certa desestabilização no ritmo vital de outros animais, com suas passagens que envolvem o "roubo" de alimentos em alguns viveiros, implicando maior demanda de alimentos para as 
espécies. O exemplo mais evidente foi quando ocorreu o deslocamento das araras para uma estrutura elevada - foram construídas duas coberturas para as aves e seus comedouros, com a extensão de alguns troncos conectados para o livre trânsito dos psitacídeos - situada sobre o lago dos peixes e dos marrecos, interconectada ao recinto onde permanecem; a partir de então, percebeu-se que com a abertura dos comedouros os macacos continuaram, como de costume, a sua busca por alimentos, pois as aves não apresentavam qualquer empecilho quanto a isso, exigindo, assim, a vigilância por parte da equipe de biólogos, que afastavam os micos com finas borrifadas de água, segundo o biólogo Neto, até que "os micos se acostumassem" a não pegar os alimentos.

$\mathrm{O}$ excessivo descarte de lixo, com uma significativa quantidade de matéria orgânica, é um atrativo a mais no forrageio dos pequenos primatas, que deambulam ávidos pelas lixeiras se banqueteando com resíduos. Se há uma preocupação dos técnicos do zoo com animal welfare (Dawkins, 2004) das espécies confinadas nos recintos, quando se trata dos micos de vida semilivre não é diferente. Há, sabidamente, dificuldade no controle sobre os bandos que investem sobre as lixeiras, assim como uma preocupação com o fato de que os humanos alimentam os macacos com comidas que não sejam frutas. Existem, ainda, problemas relacionados aos conflitos que emergem no seio dos próprios bandos, como indica o biólogo Távison (em 16/06/2015):

Aqui acontece às vezes que eles brigam entre eles, sei lá, por liderança do bando, aí eles brigam, se machucam. Um dia desses a gente encontrou um caído, que estava meio ferido, aí a gente pega, traz para tratar, depois do tratamento a gente tenta reintegrar ao bando, porque eles são animais que vivem em bando, isoladamente não seria muito bom para ele, não iria sobreviver.

Porém, assim que algum membro do setor da fauna percebe qualquer problema em um macaco, relacionado ao seu comportamento, hábitos alimentares, ferimentos, entre outros, o mesmo é capturado com o uso do "sonar" (rede empregada para a atividade) e encaminhado para a quarentena, sob estrita supervisão da equipe. Os animais apresentam comportamentos diferenciados em situações de desconforto, principalmente pela multiplicidade de agenciamentos efetuados no ambiente com os humanos, operantes na ingestão de alimentos não recomendáveis, doenças provindas de fungos e outros agentes etiológicos, resultando, assim, em aspectos que afetam desde o apetite até suas dinâmicas reprodutivas no Bosque. 
No decorrer do dia os macacos obtêm alimentos diversos que são oferecidos pelos visitantes, apesar das recomendações realizadas pela administração e pela equipe da fauna local. Não é raro observar as pessoas distribuindo alimentos altamente danosos à saúde animal, tais como pastéis, tapiocas, churros, biscoitos, bombons e balas, entre outros. É preciso, dessa forma, um maior controle e um movimento mais intenso dos técnicos nos dias de maior movimento de pessoas, em especial nos domingos. Em certos dias é possível observá-los descendo pela fiação até as lixeiras, quando revolvem o material e dispersam resíduos, nutrindo-se dos restos de alimentos que podem ser altamente prejudiciais.

Em determinadas situações os micos são intensamente fotografados pelos visitantes, que, movidos pela insaciabilidade do olhar fotográfico (Urry, 1992) e por certo voyeurismo ligado ao exótico, buscam um registro seja nas árvores ou nas imediações dos viveiros, uma vez que são constantemente vistos circulando pelos espaços e negociando a visualidade em troca de comida fácil.

Das paisagens do Bosque emanam imagens sensíveis e dinâmicas relacionadas a experiências de caráter biocultural. Nelas, a presença do biodiverso está entrelaçada aos construtos humanos, sendo difícil estabelecer cisões no continuum cultura-natureza ali presente, diante da proliferação de formas híbridas que emergem de naturalcultural encounters (Fuentes, 2010). Tais paisagens, no nosso ponto de vista, seriam rotineiramente evocadoras de um fértil "campo de possibilidades" (Velho, 1994), especialmente quanto às interações entre humanos e não humanos no mundo urbano. Existe, assim, uma malha complexa de engajamentos (Kohn, 2007) abertos que se delineiam a partir de devires humanos e não humanos em relação, desdobrando-se numa ecologia do possível no mundo urbano, envolvendo uma ecologia dos fluxos de energias e de matérias, por certo, mas também de símbolos.

\section{Dos galhos às grades, percorrendo zonas de contato}

Numa manhã ensolarada (em 24/04/2015), por volta das sete e meia da manhã, caminhamos pela calçada na avenida Rômulo Maiorana, localizada no bairro do Marco, cidade de Belém. Estávamos no entorno do Jardim Botânico Bosque Rodrigues Alves e seguimos em direção à barraca do Cláudio, localizada na esquina com a avenida Lomas Valentinas, onde se vende café da

Horizontes Antropológicos, Porto Alegre, ano 23, n. 48, p. 99-127, maio/ago. 2017 
manhã, tapiocas e pães aos habitués que diariamente vem ao local realizar o desjejum. Se estávamos interessados no café servido na banca, entendida enquanto espaço de sociabilidade comensal de significativa frequentação no contexto do bairro, algo mais nos estimulava a visitar o local, pois existem outros habitués que circulam naquele ponto além dos humanos.

A nossa intenção naquele dia era a de acompanhar as possíveis interações envolvendo humanos e a intensa movimentação de pequenos micos, pois comumente esses animais visitam o local em busca de alimentos disponíveis, devido ao fato de que uma grande quantidade de pessoas realiza as suas refeições matinais na barraca do Cláudio - mas não apenas nela ${ }^{6}-$, jovem que mantém o negócio familiar voltado à venda de lanches.

Naquele dia aproveitamos também para tomar um café. Logo avistamos um bando de macacos movimentando-se ao longo do gradil, à distância. Venciam o trajeto rapidamente. Ficou evidente que desenvolveram habilidades para se deslocarem sobre as grades, apoiando-se nas suas extremidades pontiagudas, ações que realizaram com extrema agilidade até alcançarem o estabelecimento de Cláudio, desde os galhos dos quais desciam até o deslocamento sobre construto humano e a aproximação com as pessoas. Portanto, vinham ao encontro da barraca movidos pela intenção de estabelecer contato com os humanos que ali se alimentavam. Havia uma intencionalidade evidente e uma abertura às negociações interespécies pautadas no deixar-se ver e/ou tocar e o comensalismo.

A forma que encontraram para alcançar o gradil e sua extensão se constituía a partir da aproximação da ramagem situada nas extremidades dos galhos; em meio à grande agitação e vocalizações dos primatas, seguiu-se a descida pela extensão vertical dos postes de iluminação e galhos da flora que, porventura, tocavam as grades e a murada.

Ao chegarem próximo da barraca diminuíram o ritmo da movimentação, posicionaram-se e avaliaram o cenário que se apresentava a eles. Há intencionalidade e agência nos seus gestos que se revelam nos primeiros olhares que trocam com os humanos - interesses recíprocos, mas diversos, os aproximam -, pois se instaura ali uma relação face a face entre primatas humanos e não

6 Fonseca da Silva (2014) mostrou a complexidade existente no entorno do Bosque, especialmente no que se refere às atividades dos trabalhadores informais naquele contexto. 
humanos. Uma relação proxêmica envolvendo negociações próprias ao jogo social de proximidade-distância colocaria os diferentes grupos em interação.

O movimento de descerem através das barras de ferro e de se agarrarem a elas, apoiando-se e permanecendo na vertical em posição de agenciarem alimentos é, rapidamente, modificado para ações mais diretas de interação, tais como subir nas cadeiras e, mesmo, descer até a calçada, compartilhando alimentos juntamente com as pessoas no local: recebem pães e tapiocas recheados, mas também roubam alimentos das mãos das pessoas. $\mathrm{O}$ recebimento de alimentação, por vezes, segue-se de conflitos e gritos estridentes entre membros do bando, na disputa de um naco de pão ou de uma tapioca.

A relação de Cláudio com os animais, no entanto, é ambígua. Ele parece saber que os macacos tanto atrapalham os seus clientes quanto são um atrativo para a frequentação de sua banca. O jovem espanta os primatas com um pano de prato que segura, girando-o com o braço erguido que, não raro, é acompanhado de sons e de falas do tipo "vão 'bora!" - geralmente, quando a situação de pilhagem está incontrolável, prejudicando o seu negócio, como foi possível observar em diferentes momentos.

Naquele dia, como eram esperadas, as interações entre micos-de-cheiro e as pessoas aconteceram. Cláudio preparou uma tapioca e a segurou com a mão para que alguns macacos ${ }^{7}$ pudessem pegá-la. Divertia-se ao alimentar os animais: primeiro, fingia entregar os pedaços de tapioca, puxando-a em seguida para evitar que pegassem e, por fim, entregava-os. Alguns primatas mais afoitos desceram ávidos pela iguaria, outros, temerosos e desconfiados, permaneciam no gradil à espera que pudessem receber algum tipo de alimento do rapaz.

Enquanto olhávamos a cena e preparávamos as câmeras fotográficas para registrarmos a explosão do evento interespecífico que presenciávamos, um dos primatas que observava o entorno - e, por certo, nos observava - desceu rapidamente pelo gradeado, em nossa retaguarda, pulando entre as cadeiras em que havíamos sentado. Entre o espanto e admiração humanos, ele nos encarou a meia altura por alguns instantes e tomou uma de nossas tapiocas.

\footnotetext{
Aqui é preciso fazer uma ressalva destacando o caráter positivo, no sentido simmeliano (Simmel, 1983) da sociação, entre micos e humanos, ou ainda, no sentido de ressaltar a interação afetuosa com os não humanos em meio urbano, mas isso não significa dizer que dar tapiocas aos primatas seja adequado - e saudável - para eles enquanto animais silvestres.
} 
Aos pulos alcançou o gradil e banqueteou-se com o repasto nos galhos de uma árvore até que se dispersou no bando, desaparecendo em seguida no Bosque.

Os micos são vistos rotineiramente deslocando-se pelos gradis que aparecem em várias partes do Bosque. Eles circulam comumente pelos estratos verticais da floresta, desde onde os galhos estendem-se à cerca que contorna toda a extensão do Bosque e, por certo, a partir de onde acessam as fiações elétricas, servindo de linhas à movimentação dos animais e que, por isso, aparecem como definidoras de percursos que se estendem até mesmo ao chão, às calçadas e em determinadas situações à travessia da avenida movimentada que contorna a área verde urbana, quando vão em busca de frutas no carrinho do vendedor situado no outro lado da avenida.

"A questão desses macacos é - na verdade dos macacos em si - é que eles trabalham por bando", vaticinou o tratador Moisés durante o preparo dos alimentos na cozinha (em 03/06/2015). Movimentam-se em diferentes horários: pela manhã, por volta das sete e meia às oito e meia, e um pouco mais tarde, às dez horas. À tarde circulam com maior intensidade entre as quatro e cinco horas. Nota-se que os animais retiram-se para as copas da cobertura vegetal nos períodos de altas temperaturas, incluindo o período entre 12 até as 14 horas, mesmo diante do sombreamento oferecido pela flora sobre as calçadas e gradeados.

O que parece claro é que tais temporalidades constituem-se em momentos de maior ou menor visibilidade e, por isso, de agência por parte dos primatas, onde a sua presença conspícua se evidencia no estabelecimento de zonas de contatos e de negociações movidas pelo jogo de proximidade-distância, quando se intensificam as interações interespecíficas diante de uma rítmica de (des)encontros e de atividades diárias com os humanos. Tais interações se efetivam em lugares onde há maior possibilidade de receberem alimentos, sobretudo junto às bancas com comercialização de comidas (tapiocas, tacacá, batatas fritas, entre outros) que se distribuem na esquina da avenida Rômulo Maiorana com a avenida Lomas Valentinas, e na avenida Almirante Barroso no cruzamento com a segunda, perímetro extremamente movimentado e ruidoso.

Percebe-se que na banca do Cláudio os micos descem quase diariamente, misturando-se através das grades e deambulando pelo chão com os humanos, recebendo como ofertas de comidas tapiocas e pães. Descem pelas extensões de galhos, alguns ainda ultrapassam o gradeado, apontando para a problemática da poda irregular da flora. Numa manhã, em meio ao Bosque, nos arredores 
do setor da fauna, conversamos com o biólogo Távison sobre o assunto (em 16/06/2015):

- Outra coisa que a gente vê, é que essas árvores possuem os galhos muito próximos ao gradil. Há alguma medida em relação à poda?

- Sim. O setor de flora, eles tem essa preocupação junto com o setor de fauna, a gente faz esse monitoramento, também, dessas árvores que estão passando por cima do gradil para a rua. Sempre fazem uma poda, eles estão fazendo agora, estão com um projeto de podar todas as árvores que estão por cima do gradil, inclusive, não é só com os macacos que a gente tem essa preocupação, mas com as preguiças também. Tem algumas umbaubeiras que estão com os galhos para fora do Bosque, a gente está tendo essa preocupação de identificar onde, porque os animais, com o vento da chuva, o galho pode quebrar e eles caírem no meio da rua, na calçada, ou no gradil. Um dia desses caiu uma iguana no gradil e ela se machucou, caiu em uma ponta do gradil. Estamos tendo essa preocupação de fazer essa poda ao redor do Bosque, para evitar esse tipo de acidente.

Há o fluxo de animais, pois a sua circulação ocorre mediante as conexões com o entorno do Bosque, mais especificamente através da flora, pois os galhos possibilitam uma ampliação dos movimentos dos animais para além dos limites físicos do Bosque. Ou seja, ao longo de toda a sua extensão - envolvendo uma quadra inteira - existem condições para deambulações da fauna (especialmente, micos, preguiças e iguanas através das árvores, além de um número significativo de aves) e a possibilidade de ocorrerem contatos com humanos. Não raro acontecem interações envolvendo acidentes, tais como a queda de animais, principalmente preguiças, morcegos, iguanas e micos-de-cheiro. Andando pela calçada do Bosque, na avenida Rômulo Maiorana, em certa ocasião encontramos uma preguiça-comum (Bradipus variegatus) caída no chão junto a galhos quebrados. Estava desacordada devido à queda. Logo, junto à população, acionamos a equipe da fauna, que imediatamente auxiliou o animal no local. Em seguida, levaram-no à quarentena para avaliações quanto ao seu estado de saúde. Depois, foi reconduzida a uma árvore. Nota-se a necessidade constante de podas da flora no interior do Bosque. Segundo Távison (em 16/06/2015):

Um dia desses a gente encontrou um caído [mico-de-cheiro], que estava meio ferido, aí a gente pega, traz para tratar, depois do tratamento a gente tenta 
reintegrar ao bando, porque eles são animais que vivem em bando, isoladamente não seria muito bom para ele, não iria sobreviver. A gente tenta reintegrar ao bando, e às vezes acontece deles errarem o cálculo do pulo, ou pularem em um galho podre e caírem.

A configuração das imagens em torno dos micos-de-cheiro emerge a partir de um processo que ordena o mundo da cultura em relação ao mundo da natureza, via olhar civilizador (Elias, 1994) que tensiona o selvagem e o doméstico, reificando a liminaridade dos dispositivos metafísicos do zoo (Estebanez, 2008, 2010; Marvin, 2008) que conflituam "humanos civilizados" e "animais selvagens"/"exóticos" - aqui, transpostos aos animais de vida semilivre -, diante da possibilidade de seus "ataques" e da periculosidade mediante certos contatos. Amiúde tais imagens relacionam-se a uma legitimidade conferida ao ambiente natural a partir das características animais, nesse caso visto nas imagens de seus saltos, de sua força, de seus movimentos bruscos e de repousos nos galhos das árvores, por exemplo. Por certo, tais ambivalências opõem, ainda, o animal selvagem ao doméstico, remetendo, por redundância, às categorias dicotômicas de natureza e cultura, como imagens construídas por oposição excludente no mundo ocidental.

Entretanto, a complexidade dos laços interespecíficos coloca a problemática de imagens para além da referida oposição, como apontou Agustin Fuentes (2007), pois a emergência de outra imagem ligada a um conjunto de relações estabelecidas in-between (Fuentes, 2007) é possível, na medida em que os micos, como indica a etnografia, estão amplamente integrados ao convívio com os humanos na cidade, participando da economia (comensal e simbólica) em suas práticas de forrageamento e de circulação dentro e no entorno do Bosque, portanto, no contexto $d a$ cidade. Tais questões envolvem amplas atividades que possibilitam de certa forma a expansão de um hábitat na coprodução de nichos, quando os micos negociam espaços com humanos. Porém, isso não significa segurança para os primatas não humanos, pois mesmo obtendo grande simpatia e carinho de parte da população, como foi demonstrado, não sendo cativos, quando circulam também estão à mercê de maus-tratos e de outras situações que envolvem os humanos, como atropelamentos, por exemplo. Certa vez (em 13/01/2015), Távison alertou-nos sobre as situações perigosas para os micos:

Aconteceu que um rapaz queria levar [um mico-de-cheiro]. A gente não sabe com qual frequência isso acontece, se foi a primeira vez que ele tentou, não 
sabemos, nós não temos fiscalização. Não dá para colocar uma pessoa fixa aí fora fiscalizando. A gente conta com a boa vontade das pessoas, que quando veem sempre ligam, aí a gente vai lá correndo, tentar coibir esse tipo de prática.

Outros (des)encontros ocorrem principalmente numa das laterais do Bosque, mais especificamente naquela que corresponde à avenida Almirante Barroso com avenida Lomas Valentinas, onde há uma parada de ônibus com intensa circulação de pessoas e tráfego de carros, além de barracas de venda de comidas. Outro dos pontos marcantes está localizado na avenida Rômulo Maiorana: a frutaria do Seu Louro, que se localiza nos arredores de um ponto de táxi. Os macacos são comumente alimentados por passantes na calçada e nos gradeados, algumas vezes com as pessoas subindo no gradil e disponibilizando o alimento no topo das lacunas de entremeio, ou simplesmente deixando bananas nos moirões e nos gradis. Todavia, em certas ocasiões os micos são vistos descendo pelo gradeado e, a partir daí, atravessando a rua em busca de frutas. Durante uma conversa com o rapaz que ajuda Seu Louro na banca, um dos micos fez a travessia, e logo foi auxiliado por um taxista que estava em seu local de trabalho. Na ocasião (em 04/07/2015) o rapaz narrou sobre tal itinerário:

E os alimentos eles descem e pegam... Descem. Comem na mão. Os caras dão! Aí eles pegam na mão. Eles descem e vão embora, sobem de novo. Tem gente que passa aí todo dia? Todo dia! Tem uns que vêm aqui e compram uma bananinha, especial para os macaquinhos, aí a gente dá para eles. Aí levam e dão lá para eles.

Quando os micos realizam a travessia da rua, recebem o alimento e retornam em aliança com os taxistas, ou as pessoas da banca (vendedores, clientes e outros personagens que sociabilizam em tais espaços), ajudando-os quando necessário e até fazendo com que motoristas de carros diminuam a velocidade de seus veículos ao sinalizarem a passagem dos pequenos primatas. Em outra esquina - na Perebebuí, no cruzamento com Rômulo Maiorana -, os micos são vistos descendo o gradil e atravessando a rua em direção à barraca de coco. Em conversa com o filho do dono do estabelecimento, Ribamar, ele afirmou que além de descerem também vasculham o lixo. "Esses macacos são vira-latas. Mexem no lixo e derrubam!", contou-nos em tom bem-humorado. Porém, em algumas situações não é 
possível evitar acidentes relacionados a tais movimentos. Sobre os perigos concernentes às passagens pela rua, o tratador Moisés e o biólogo Távison argumentaram:

É... Isso a gente sempre orienta as pessoas a não fazerem isso, por quê? Porque esses animais, às vezes até a pessoa tem uma boa vontade, compra fruta para querer dar, só que assim, o animal ele acaba tendo... É, quando ele olha a pista [...] [no] outro lado, aquilo que já foi dado pra ele, ele olha aquilo como sendo território dele, então quando ele atravessa a pista ele não tem o senso de segurança. Ele olha ali, eu recebi comida ali, então é seguro eu atravessar. Isso é muito perigoso, nós já tivemos alguns acidentes com macacos... Macaquinhos aqui na Vinte e Cinco que foram atropelados infelizmente, mas assim [...] vai e compra, as pessoas acostumam, dão banana [...] um vai e desce, pega e come, desce e volta, e pensa que a área fora do parque se torna segura para ele, aí que é, aí que ocorre os acidentes. Acabam sendo atropelados, machucados, então geralmente a gente já faz a poda, isso é, uma pessoa de fora, a gente faz a poda na lateral do Bosque para deixar as árvores bem altas para que eles não venham a descer pelas, pelas, pelos galhos e pelas grades, precisa ter todo esse cuidado justamente para evitar isso, mas infelizmente é difícil de controlar [...]. (Moisés, em 31/08/2014)

- Há, ou houve algum problema, algum acidente ao redor do Bosque, ou aqui dentro com esses micos-de-cheiro?

- Aconteceu, mas quando eu não trabalhava aqui. Eu ouvi a história de que aqui atrás tem uma banca de frutas, né!? Aí um deles foi querer atravessar para pegar comida lá, aí ele foi atropelado por um carro. (Távison, em 16/06/2015).

As ruas enquanto espaços praticados no contexto do entorno do Bosque compõem-se da vida urbana com os micos, mediante as dimensões relacionais que estes estabelecem através delas, ou seja, a partir de suas itinerâncias com os humanos, os pequenos primatas praticam-nas à sua maneira. Ora, neste sentido, compartilham com os humanos uma ecologia de odores e de sabores que envolvem os cheiros de alimentos palatáveis nas barracas (suas instalações, ocupações nas calçadas e meio-fio), os horários propícios às descidas e as dimensões ecossistêmicas que facilitam suas agências (clima, flora, entre outros) e possibilitam a sua presença na tessitura da malha urbana com seus ritmos e interações coexistindo num espaço fluido, enquanto (des)dobramento de socialidades humanimais.

Horizontes Antropológicos, Porto Alegre, ano 23, n. 48, p. 99-127, maio/ago. 2017 


\section{Traçando linhas, indicando nós}

A possibilidade de observar as interações interespecíficas na urbe emergiu em nossa pesquisa através de uma investigação etnográfica, que se desdobrou desde o exercício de uma etnografia no mundo urbano, na medida em que, ao experimentarmos as caminhadas como formas de vivenciar a dinâmica de seus espaços, considerando as interações humanas e não humanas, acessamos dimensões sociais que constituem narrativas na/da cidade que falam de suas paisagens coexistenciais interespecíficas.

Nesses termos, as experiências cotidianas de interação entre humanos e macacos no Bosque Rodrigues Alves, e em seu entorno, são efetuadas mediante o estabelecimento de negociações de sentido que se revelam na ocupação/ construção de nichos numa zona de contato, vivenciada de forma interespecífica através de distanciamentos e de proximidades que instauram posições diferenciais no jogo das socialidades. As últimas sempre negociadas, emergindo como expressões formais de interações humanimais nas paisagens praticadas do Bosque.

Tais posições surgem não somente pela existência de grades de ferro que separam os micos dos animais em cativeiro na relação de copresença no zoo, mas, também, mediante os engajamentos interespecíficos que acontecem no interior do Bosque - envolvendo a equipe da fauna, que objetiva com suas práticas e manejos a conservação da biodiversidade confinada ou de vida semilivre, buscando o bem-estar animal - e, em seu exterior, com passantes, comerciantes, taxistas, entre outros, que interagem cotidianamente alimentando os micos-de-cheiro, estabelecendo, principalmente, relações recíprocas.

Os (des)encontros diários nas calçadas entre humanos e micos também compreendem falas, olhares e toques, ou ainda, posições e gestos assumidos que indicam formas de relação constituídas na temporalidade compartilhada dos espaços praticados, no entorno do Bosque. Sendo assim, da extensão vertical do gradil de onde o mico se posiciona, o seu olhar encontra o do humano que para e o observa ou caminha observando-o, aponta e indica, estende a mão e o alimenta, num jogo de ações que indicam outras ações - lembrando as reflexões de Humberto Maturana $(1990,1992)^{8}$-, obtendo respostas

${ }^{8} \mathrm{O}$ jogo interacional, neste caso, tem relação com o fato de que "o que se observa depende do observador" e de que, ao observar e especificar "determinada coisa como uma unidade", ele identifica o restante

Horizontes Antropológicos, Porto Alegre, ano 23, n. 48, p. 99-127, maio/ago. 2017 
inteligentes dos micos. Enfim, estabelecendo comunicações interespecíficas, pois há interagências mútuas vividas nas socialidades que respeitam itinerários, as espacialidades dos recintos e seus entornos, a malha de elementos que compõem os materiais e os espaços onde habitam os animais, o gradil, as calçadas, as ruas, entre outros elementos presentes no mundo urbano belenense que configuram uma ecologia urbana que merece ser mais bem compreendida.

Finalmente, etnografias multiespecíficas (Kirksey; Helmheich, 2010) como a que propomos neste estudo, permitem um aprofundamento sobre as atitudes e as percepções acerca do outro não humano, pois a existência dos animais - e quando falamos animais fica difícil separá-los dos vegetais - dá-se conjuntamente àquela dos humanos ao longo do Bosque, uma vez que ambos figuram naquele contexto citadino a partir de seus agenciamentos nas paisagens, por certo, desde as suas diferenças coligadas e de produção de complexidades.

\section{Referências}

BALDWIN, J. D. The behavior of squirrel monkey (Saimiri) in natural enviromentals. In: ROSENBLUM, L. A.; COE, C. L. (Ed.). Handbook of squirrel monkey research. New York: Plenum Press, 1985. p. 35-53.

BALDWIN, J. D.; BALDWIN, J. I. The squirrel monkeys, genus Saimiri. In: COIMBRA FILHO, A.; MITTERMIER, R. (Ed.). Ecology and behavior of neotropicals primates. Rio de Janeiro: Academia Brasileira de Ciências, 1981. p. 277-330.

BERGER, J. Why look at animals?. London: Penguin Books, 2009.

BERQUE, A. Paisagem-marca, paisagem-matriz: elementos da problemática para uma geografia cultural. In: CORRÊA, R. L.; ROSENDAHL, Z. (Org.). Paisagem, tempo e cultura. Rio de Janeiro: Ed. UERJ, 1998. p. 84-91.

BICCA MARQUES, J. C; SILVA, V. M.; GOMES, D. Ordem primates. In: REIS, N. et al. (Ed.). Mamíferos do Brasil. Curitiba: Gráfica Oficial do Estado do Paraná: Sociedade Brasileira de Zoologia, 2006. p. 101-148.

como cenário (Maturana, 1990) e, neste sentido, se encontra imerso numa malha de relações ecológicas complexas no contexto em que se dão as interações. 
BOSQUE completa 132 anos com ampla programação. Agência Belém, 25 ago. 2015. Disponível em: <http://www.agenciabelem.com.br/noticias/ detalhes/116444>. Acesso em: 30 maio 2016.

DAWKINS, M. S. Using behaviour to assess animal welfare. Animal Welfare, Wheathampstead, v. 13, p. 3-7, 2004.

DE CERTEAU, M. A invenção do cotidiano: artes de fazer. Petrópolis: Vozes, 1994.

DELEUZE, G.; GUATTARI, F. Mille plateaux: capitalisme et schizophrénie. Paris: Minuit, 1980.

DESPRET, V. From secret agency to interagency. History and Theory, Malden, v. 52, p. 29-44, 2013.

ESCOBAR, A. O lugar da natureza e a natureza do lugar: globalização ou pós-desenvolvimento? In: LANDER, E. (Org). A colonialidade do saber: eurocentrismo e ciências sociais. Perspectivas latino-americanas. Buenos Aires: CLACSO, 2005. p. 133-168. (Colección Sur Sur).

ELIAS, N. O processo civilizador: uma história dos costumes. Rio de Janeiro: Jorge Zahar, 1994.

ESTEBANEZ, J. Les jardins zoologiques ou l'exotique a porte de main. Le Globe, Genève, n. 148, p. 49-67, 2008.

ESTEBANEZ, J. Ceux qui sont proches: les soigneurs au zoo. Sociétés, Bruxelles, v. 2, n. 108, p. 47-57, 2010.

FAVRET-SAADA, J. Être affecté. Gradhiva: Revue d'Histoire et d'Archives de l'Anthropologie, Paris, n. 8, p. 3-9, 1990.

FONSECA DA SILVA, C. R. Trabalho, sociabilidade e convivência nas paisagens do Bairro do Marco - Belém, PA. 2014. Trabalho de Conclusão de Curso (Bacharelado em Ciências Sociais)-Faculdade de Ciências Sociais, Universidade Federal do Pará, Belém, 2014. 
FUENTES, A. Monkey and human interconnections: the wild, the captive, and the in-between. In: CASSIDY, R.; MULLIN, M. (Ed.). Where the wild things are now: domestication reconsidered. Oxford: Berg, 2007. p. 123-145.

FUENTES, A. Natural cultural encounters in Bali: monkeys, temples, tourists and ethnorimatology. Cultural Anthropology, Washington, v. 25, n. 4, p. 600$624,2010$.

FUENTES, A.; SHAW, E.; CORTES, J. Qualitative assessment of macaque tourist sites in Padangtegal, Bali, Indonesia, and the Upper Rock Nature Reserve, Gibraltar. International Journal of Primatology, Dordrecht, n. 28, p. 1143-1158, 2007.

GORDO, M. et al. The challenges of survival in a concrete jungle: conservation of the Pied Tamarin (Saguinus bicolor) in the urban landscape of Manaus, Brazil. In: MARSH, L.; CHAPMAN, C. (Ed.). Primates in fragments: complexity and resilience. New York: Springer, 2013. p. 357-370.

HALL, E. A dimensão oculta. Lisboa: Relógio D’água, 1986.

HARAWAY, D. A companion species manifesto: dogs, people, and significant otherness. Chicago: Prickly Paradigm, 2003.

INGOLD, T. Bringing things to life: creative entanglements in a world of materials. Manchester: University of Manchester, 2010. (Realities Working Paper, 15).

INGOLD, T. Being alive: essays on movement, knowledge and description. New York: Routledge, 2011.

KIRKSEY, S. E.; HELMREICH, S. The emergence of multispecies ethnography. Cultural Anthropology, Washington, v. 25, n. 4, p. 545-557, 2010 .

KOHN, E. How dogs dream: amazonian natures and the politics of transspecies engagement. American Ethnologist, Arlington, v. 34, n. 1, p. 3-24, 2007. 
LEITE, G.; DUARTE, M.; YOUNG, R. Human-marmoset interactions in a city park. Applied Animal Behaviour Science, Amsterdam, n. 132, p. 187-192, 2011.

MAGALHÃES, T. Ecologia comportamental de macaco-de-cheiro (Saimiri sciureus) em ambiente seminatural, Belém, Pará. 2008. Trabalho de Conclusão de Curso (Bacharelado em Ciências Biológicas)-Instituto de Ciências Biológicas, Universidade Federal do Pará, Belém, 2008.

MAGNI, C. Nomadismo urbano: uma etnografia sobre moradores de rua de Porto Alegre. Santa Cruz do Sul: Edunisc, 2006.

MARVIN, G. L'animal de zoo: un rôle entre sauvage et domestique. Techniques \& culture, Paris, v. 50, n. 1, p. 102-119, 2008.

MATURANA, H. O que se observa depende do observador. In: THOMPSON, W. I. (Org.). Gaia: uma teoria do conhecimento. São Paulo: Gaia, 1990. p. 61-76.

MATURANA, H. Conhecer o conhecer. Ciência Hoje, São Paulo, v. 14, n. 184, p. 44-49, 1992.

PINK, S. Walking with video. Visual Studies, Abingdon, v. 22, n. 3, p. 240252, 2007.

PINK, S. A urban tour: the sensory sociality of ethnographic place-making. Ethnography, London, v. 9, n. 2, p. 175-196, 2008.

PINK, S. Doing sensory ethnography. London: Sage, 2009.

RADHAKRISHNA, S.; SINHA, A. Less than wild? Commensal primates and wildlife conservation. Journal of Biosciences, Bangalore, v. 36, n. 5, p. 749$753,2011$.

SILVEIRA, F.; SILVA, M. Acerca do olhar do outro, ou sobre "tratadores" e animais em cativeiro. Por uma etnografia no "zoo" em contexto urbano (Belém-PA). Caderno Eletrônico de Ciências Sociais, Vitória, v. 3, n. 1, p. 54-74, 2015. 
SIMMEL, G. Sociologia. In: MORAES FILHO, E. (Org.). Simmel. São Paulo: Ática, 1983.

URRY, J. The tourist gaze and the "environment". Theory, Culture \& Society, London, v. 9, p. 1-26, 1992.

VELHO, G. Projeto e metamorfose: antropologia das sociedades complexas. Rio de Janeiro: Jorge Zahar, 1994.

WOLCH, J. Zoopolis. Capitalism Nature Socialism, Abingdon, v. 7, n. 2, p. 21-47, 1996.

Recebido em: 31/05/2016

Aprovado em: 01/03/2017 